\title{
Programas de iluminação para poedeiras semi-pesadas
}

\author{
Clóvis Eliseu Gewehr ${ }^{1 *}$ \\ Vladimir de Oliveira ${ }^{2}$ \\ Marcos Rosniecek ${ }^{3}$ \\ Diogo Davi Follmann ${ }^{4}$ \\ Ana Maira de Cezaro ${ }^{3}$

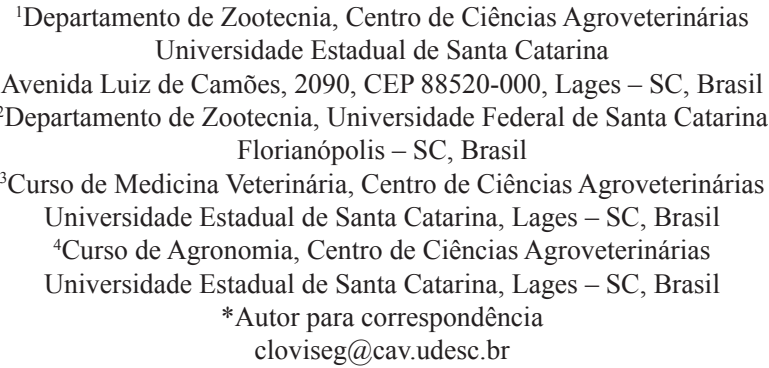

Submetido em 26/02/2011

Aceito para publicação em 08/10/2011

\section{Resumo}

Com o objetivo de avaliar diferentes programas de iluminação para poedeiras de alto desempenho, o experimento foi conduzido utilizando-se 420 poedeiras semipesadas criadas sobre cama durante 140 dias, dividido em cinco períodos de 28 dias. Foram utilizados três programas: contínuo de $16 \mathrm{~h}$ de luz e $8 \mathrm{~h}$ de escuro; programa intermitente com duas fotofases de 2 min equidistantes em $16 \mathrm{~h}$ entre a luz natural e programa com apenas luz natural decrescente. Avaliou-se consumo de ração (g/ave/dia), produção de ovos (\%/ave/dia), peso de ovos (g), massa dos ovos (g), conversão alimentar $(\mathrm{g} / \mathrm{g})$ e gravidade específica dos ovos $(\mathrm{g} / \mathrm{cm} 3)$. Os resultados foram submetidos a analise de variança e as diferenças ao teste de Tukey (5\%). Aves submetidas ao programa intermitente e luz natural decrescente tiveram menor $(\mathrm{P}<0,05)$ produção de ovos, consumo de ração e peso de ovos em relação ao programa contínuo de $16 \mathrm{~h}$. Programa intermitente com fotofases de $2 \mathrm{~min}$ e programa de luz natural decrescente não são eficientes para ser fornecido às poedeiras semi-pesadas no início do período de postura.

Palavras-chave: Avicultura, Fotoperíodo, Galinhas, Programas de luz

\section{Abstract}

Lighting programs for semi-heavy layers. With the goal of evaluating different lighting programs for high performance layers, an experiment was conducted using 420 semi-heavy laying hens reared on beds for 140 days. The time of the study was divided into five periods of 28 days. We used three programs: $16 \mathrm{~h}$ of continuous light and $8 \mathrm{~h}$ of dark; an intermittent program with two photophases of $2 \mathrm{~min}$ and $16 \mathrm{~h}$ of light; and a program 
with only naturally decreasing light. We evaluated food intake (g/bird/day), egg production (\%/hen/day), egg weight $(\mathrm{g})$, egg mass $(\mathrm{g})$, feed conversion $(\mathrm{g} / \mathrm{g})$ and egg specific gravity $(\mathrm{g} / \mathrm{cm} 3)$. The results were submitted to an analysis of variance and the differences to Tukey's test $(5 \%)$. Birds subjected to the intermittent and decreasing natural light programs had lower $(\mathrm{P}<0.05)$ egg production, feed intake and egg weight in relation to $16 \mathrm{~h}$ of continuous light. The program with $2 \mathrm{~min}$ photophases and the program with naturally decreasing light are not efficient enough to be given to the the semi-heavy layers at the beginning of the laying phase..

Key words: Chickens, Photoperiod, Poultry industry, Light programs

\section{Introdução}

Programas de luz são usados por produtores para estimular o aparelho reprodutor das poedeiras com o objetivo de aumentar a produção de ovos (ETCHES, 1996). Estes programas necessitam do uso da iluminação artificial em suplementação à luz natural. Tal situação faz com que a energia elétrica seja contabilizada no custo de produção de ovos. O uso da iluminação artificial possibilita aumentar em 20 a $40 \%$ o número de ovos por poedeira em cada ciclo (COTTA, 2002).

Os programas de iluminação utilizados na criação de aves de postura são classificados de acordo com o fotoperíodo, em hemerais e ahemerais. Programas hemerais são compostos de períodos de $24 \mathrm{~h}$, distribuídos em fase clara (fotoperíodo ou fotofase) e fase escura (escotoperíodo ou escotofase). Em instalações abertas, em que é aproveitada a luz natural, utilizam-se somente programas hemerais (CAMPOS, 2000).

Programas hemerais podem ser classificados em contínuos e intermitentes. Nos programas contínuos, a iluminação artificial é acrescida à natural para formar um fotoperíodo longo contínuo, enquanto nos intermitentes há uma combinação alternada de períodos de luz (fotofases) com escuros (escotofases). Quando os programas intermitentes possuem horas de fotofases e escotofases semelhantes, diz-se que o programa é simétrico (GEWEHR; FREITAS, 2007). Um programa de iluminação intermitente pode ser definido como aquele formado por mais de um período de luz (fotofase) e de escuro (escotofase) em ciclos de $24 \mathrm{~h}$.

Regimes luminosos intermitentes foram amplamente estudados em aves criadas em galpões fechados e, atualmente, são utilizados com sucesso em criações comerciais. As vantagens da aplicação de programas intermitentes em galpões fechados são inquestionáveis.
Seu uso em galpões abertos, caso dos galpões brasileiros, deve ser considerado. $\mathrm{Na}$ atualidade, alguns estudos comprovam esta aplicabilidade (FREITAS et al., 2005; 2010; GEWEHR et al., 2005, GEWEHR; FREITAS, 2007).

Programas intermitentes são fundamentados na "noção do dia subjetivo". Esta teoria supõe que uma ave adulta em produção, já anteriormente sensibilizada em um fotoperíodo longo contínuo, necessita apenas da informação de que o seu dia biológico está iniciando ou terminando. As aves ignoram períodos de escuro dentro do intervalo de tempo necessário para estimular a postura. Esta informação pode ser dada através de um simples flash de luz. A ave irá ignorar períodos intermediários de escuridão (GEWEHR, 2003).

Melo et al. (2006) avaliaram os efeitos dos programas contínuo e intermitente sobre o desempenho de codornas (Coturnix coturnix) na fase inicial de postura. O programa intermitente utilizou um regime com três fotofases em $17 \mathrm{~h}$ e um escotoperíodo de $7 \mathrm{~h}$ (0,5L:1E:10,72L:3,75E:0,5L:7E no solstício de inverno). O programa contínuo apresentou um fotoperíodo de $17 \mathrm{~h}$ e escotoperíodo de $7 \mathrm{~h}$ (17L/7E). Os resultados obtidos demonstram que não houve diferença significativa no consumo de ração, no entanto a produção de ovos no regime intermitente foi maior que no contínuo. Não houve diferença na qualidade de ovos. Ressalta-se que esse experimento foi conduzido em uma granja comercial de codornas em, em que os resultados foram obtidos em condições práticas, cujo objetivo da criação das aves é o lucro com a venda dos ovos. Os resultados deste trabalho também revelam um novo paradigma com relação aos programas intermitentes. Trata-se de um precursor em demonstrar que estes programas podem ser adotados a partir do início do período de postura. Até então, sabia-se que as aves necessitavam de um período de adaptação, 
e não poderiam ser iniciados antes das 36 semanas de idade, no caso de galinhas (ROWLAND, 1985).

Pesquisas realizadas até o momento com programas de iluminação intermitente em galinhas e codornas comerciais criadas em galpões abertos apresentam resultados positivos e promissores. $\mathrm{O}$ uso da iluminação intermitente em criações de aves poedeiras se mostrou altamente eficiente e viável. Trata-se de uma importante ferramenta de manejo para ser aplicada em países de clima tropical, os quais fazem uso de instalações abertas para aproveitar a luminosidade natural. A iluminação intermitente possibilita a redução do consumo de energia elétrica usada para estimular o aparelho reprodutor em galpões abertos sem redução no desempenho zootécnico e sem afetar a qualidade dos ovos (GEWEHR; FREITAS, 2007).

Ernst et al. (1987) concluíram que, devido ao melhoramento genético, a idade para fotoestimular as aves deve ser reavaliada periodicamente para otimização da produção. Neste contexto sabe-se que as linhagens de poedeiras modernas vêm sofrendo uma intensa pressão de seleção para melhorar índices produtivos (aumento do número de ovos e redução do consumo alimentar). Neste ínterim, tem-se a dúvida se para estas linhagens modernas de alto desempenho há ainda a necessidade da estimulação luminosa. Não obstante, cogita-se a possibilidade de redução do consumo energético luminoso com uso de programas de luz intermitente a partir do início da postura.

Charles e Tucker (1993), após revisão de vários experimentos, deduziram que as aves são tão geneticamente predispostas à postura que quase se apresentam refratárias às mudanças de regime luminoso. Também que é possível que poedeiras modernas sejam mais tolerantes a intensidades mais baixas de luz. Para Sauveur (1996), há uma perda progressiva da sensibilidade à luz devido à seleção muito intensa para a obtenção de melhores índices de postura.

Assim, este trabalho teve o objetivo de avaliar o desempenho e a qualidade de ovos de uma linhagem moderna de poedeiras semipesadas submetidas a programas de iluminação contínuo de $16 \mathrm{~h}$, intertemitente com fotofases de $2 \mathrm{~min}$ e luz natural decrescente no início da fase de postura.

\section{Material e Métodos}

Um experimento com duração de 140 dias, divididos em cinco períodos de 28 dias, estendendose de janeiro a junho de 2010, com 420 poedeiras semipesadas de alto desempenho foi realizado no Setor de Avicultura do Departamento de Produção Animal e Alimentos do Centro de Ciências Agroveterinárias da UDESC - Lages/SC. O trabalho foi conduzido em galpão aberto de alvenaria, sendo as aves criadas sobre cama e distribuídas aleatoriamente em 30 boxes de $2 \mathrm{~m}^{2}$, cada um equipado com um comedouro tubular e um bebedouro pendular e 3 ninhos. Foram alojadas 14 aves em cada box, constituindo as parcelas experimentais.

Foram utilizados os seguintes programas de iluminação (tratamentos):

Contínuo de 16h de luz/dia: as lâmpadas foram acesas às $4 \mathrm{~h}$ e apagadas ao amanhecer; acesas novamente às $17: 30 \mathrm{~h}$ e apagadas às $20 \mathrm{~h}$, de forma que as aves recebessem um fotoperíodo contínuo de $16 \mathrm{~h}$ e um escotoperíodo de $8 \mathrm{~h}$. Este programa é o recomendado pelo manual da linhagem utilizada. Intermitente: as lâmpadas foram acesas às $4 \mathrm{~h}$ e apagadas após $2 \mathrm{~min}$ (fotofase 1 ) seguindo escuro (escotofase 1) até o amanhecer e a partir daí a luz natural do dia (fotofase 2) até o anoitecer; seguiu período escuro (escotofase 2) sendo as lâmpadas acesas novamente às 19:58h e apagadas às $20 \mathrm{~h}$ (fotofase 2). Este programa foi composto por três fotofases e duas escotofases em 16h, sendo que as escotofases 1 e 2 aumentaram em função do encurtamento do fotoperíodo natural.

- Contínuo com luz natural: as aves receberam somente o fotoperíodo natural decrescente. No início do período de avaliação as aves receberam 12:56h de luz natural e ao final 10:07h.

Para execução deste trabalho, o galpão foi dividido em três ambientes utilizando lona de plástico preta não translúcida, impedindo a passagem de luz de um ambiente para outro.

$\mathrm{Na}$ fase de crescimento, como a luz natural era crescente, as aves receberam um fotoperíodo constante de $15 \mathrm{~h} / \mathrm{luz} /$ dia (natural + artificial) a partir da $6^{\mathrm{a}}$ semana. A ração na fase de crescimento foi formulada conforme 
recomendações de Rostagno et al. (2005), sendo fornecida de forma controlada conforme recomendação para a linhagem, pesando-se diariamente a quantidade de ração de acordo com o manual da linhagem utilizada. Já a água foi fornecida à vontade.

$\mathrm{Na}$ fase de postura, ração e água foram fornecidas à vontade, sendo a ração composta à base de milho, farelo de soja e calcário calcítico, conforme exigências nutricionais recomendadas por Rostagno et al. (2005). A composição dos alimentos foi baseada também nas recomendações de Rostagno et al. (2005), sendo $2.800 \mathrm{kcal} / \mathrm{kg}$ de energia metabolizável, $17 \%$ de proteína bruta, $4,2 \%$ de Cálcio e $0,375 \%$ de fósforo disponível.

A submissão das aves aos respectivos programas de iluminação teve início quando as aves atingiram o índice médio de $5 \%$ de postura que coincidiu com o início dos períodos de avaliação.

Foram avaliados: consumo de ração (g/ave/dia) em cada período; produção de ovos (porcentagem de ovos/ave/dia) sendo os ovos coletados duas vezes ao dia, às 10h e 16h30; peso de ovos (g) avaliados em balança digital com precisão de $0,01 \mathrm{~g}$ tomando-se todos os ovos íntegros de cada parcela dos dois últimos dias de cada período experimental; massa de ovos (g/ave/ dia) obtida através do produto entre a porcentagem de produção e o peso médio de ovos de cada parcela; conversão alimentar $(\mathrm{g} / \mathrm{g})$ obtida em cada período de 28 dias, através da divisão do consumo médio de ração $(\mathrm{g})$ pelo peso médio de ovos $(\mathrm{g})$; peso específico dos ovos $(\mathrm{g} / \mathrm{cm} 3)$ realizado no final de cada período experimental, com os mesmos ovos utilizados para a obtenção do peso, sendo avaliados em solução de $\mathrm{NaCl}$, com densidade variando de 1.058 a $1.102 \mathrm{~g} / \mathrm{cm}^{3}$, com gradiente de $4 \mathrm{~g} / \mathrm{cm} 3$ entre elas, determinada com o auxílio de densímetro.

Foi utilizado um delineamento experimental inteiramente ao acaso, com três tratamentos e 10 repetições. Os dados obtidos foram submetidos a análise de variância, com medidas repetidas no tempo e as diferenças ao teste Tukey (5\%), através do procedimento MIXED (STEEL et al., 1997; SAS, 2003; LITTEL et al., 2006).

\section{Resultados}

Ocorreu diferença $(\mathrm{P}<0,05)$ na produção de ovos (Tabela 1) entre as galinhas submetidas aos diferentes programas de iluminação somente no quarto e quinto períodos de avaliação. Nestes dois períodos, no programa contínuo, a produção de ovos das aves foi maior $(\mathrm{P}<0,05)$ em relação aos programas intermitente e luz natural decrescente, sendo que nestes últimos a produção foi semelhante $(\mathrm{P}>0,05)$.

O consumo de ração das aves (Tabela 1) foi semelhante $(\mathrm{P}>0,05)$ nos três primeiros períodos, entretanto no quarto e quinto período ocorreu diferença $(\mathrm{P}<0,05)$, sendo que no quarto período o consumo foi maior $(\mathrm{P}<0,05)$ no programa contínuo em relação aos demais, e no programa intermitente o consumo foi maior $(\mathrm{P}<0,05)$ em relação ao programa luz natural

TABELA 1: Produção de ovos (\% ovos/ave/dia); consumo de ração (g/ave/dia) e conversão alimentar (g/g) de poedeiras semipesadas modernas submetidas durante cinco períodos de 28 dias a programas de iluminação contínuo (CON), intermitente (INT) e luz natural decrescente (LND)*.

\begin{tabular}{cccc|ccc|ccc}
\hline \multirow{2}{*}{ Período } & \multicolumn{3}{c}{ Produção ovos } & \multicolumn{3}{c|}{ Consumo ração } & \multicolumn{3}{c}{ Conversão alimentar } \\
\cline { 2 - 10 } & CON & INT & LND & CON & INT & LND & CON & INT & LND \\
\hline 1 & 51,2 & 47,3 & 48,5 & 102,4 & 99,3 & 99,8 & 1,74 & 1,74 & 1,77 \\
2 & 94,6 & 90,8 & 92,8 & 133,3 & 129,7 & 128,9 & 2,12 & 2,17 & 2,13 \\
3 & 94,8 & 90,8 & 91,9 & 132,7 & 129,6 & 128,4 & 2,04 & 2,03 & 2,08 \\
4 & $95,9^{\mathrm{a}}$ & $89,8^{\mathrm{b}}$ & $91,0^{\mathrm{b}}$ & $140,1^{\mathrm{a}}$ & $134,3^{\mathrm{b}}$ & $126,7^{\mathrm{c}}$ & $2,13^{\mathrm{a}}$ & $2,07^{\mathrm{ab}}$ & $2,01^{\mathrm{b}}$ \\
5 & $95,3^{\mathrm{a}}$ & $88,1^{\mathrm{b}}$ & $87,1^{\mathrm{b}}$ & $139,9^{\mathrm{a}}$ & $128,1^{\mathrm{b}}$ & $124,0^{\mathrm{b}}$ & $2,06^{\mathrm{a}}$ & $1,93^{\mathrm{b}}$ & $1,89^{\mathrm{b}}$ \\
\hline $\mathrm{CV} \%$ & & 7,04 & & & 4,62 & & & 4,73 & \\
\hline
\end{tabular}

*Letras diferentes entre as variáveis na mesma linha diferem significativamente pelo Teste Tukey $(\mathrm{P}<0,05)$. 
decrescente. No quinto período o consumo de ração das aves foi maior $(\mathrm{P}<0,05)$ no contínuo em relação ao intermitente e luz natural decrescente, sendo que nestes últimos o consumo foi semelhante $(\mathrm{P}>0,05)$.

A conversão alimentar (Tabela 1) das aves foi semelhante $(\mathrm{P}>0,05)$ nos três primeiros períodos, entretanto no quarto e quinto período ocorreu diferença significativa $(\mathrm{P}<0,05)$, sendo que no quarto período a conversão foi semelhante $(\mathrm{P}>0,05)$ nos programas contínuo e intermitente, e em ambos a conversão das aves foi maior $(\mathrm{P}<0,05)$ em relação ao programa luz natural decrescente. Já no quinto período de avaliação da conversão, esta foi maior $(\mathrm{P}<0,05)$ no contínuo em relação ao intermitente e luz natural decrescente, sendo que nestes últimos a conversão foi semelhante $(\mathrm{P}>0,05)$.

A massa de ovos (Tabela 2) foi semelhante $(\mathrm{P}>0,05)$ entre os programas de luz apenas no primeiro período. Nos demais ocorreram diferenças $(\mathrm{P}<0,05)$, sendo que no segundo período nos programas contínuo e luz natural a massa foi semelhante $(\mathrm{P}>0,05)$, entretanto a massa no programa contínuo foi maior $(\mathrm{P}<0,05)$ em relação ao intermitente, enquanto que nos programas intermitente e luz natural a massa foi semelhante $(\mathrm{P}>0,05)$. Já no terceiro, quarto e quinto períodos a massa de ovos foi maior $(\mathrm{P}<0,05)$ no programa contínuo em relação ao intemitente e luz natural, sendo que entre estes a massa foi semelhante $(\mathrm{P}>0,05)$.

No peso de ovos (Tabela 2) ocorreu diferença $(\mathrm{P}<0,05)$ em todos os períodos, onde o peso no programa contínuo no primeiro, segundo, quarto e quinto período foi maior $(\mathrm{P}<0,05)$ em relação ao intermitente e luz natural, sendo que entre estes o peso foi semelhante $(\mathrm{P}>0,05)$. No terceiro período o peso dos ovos no programa contínuo e intermitente foi semelhante $(\mathrm{P}>0,05)$ e maior $(\mathrm{P}<0,05)$ em relação ao programa de luz natural.

Ocorreu diferença $(\mathrm{P}<0,05)$ no peso específico dos ovos (Tabela 2) apenas no segundo período, sendo que no programa contínuo foi maior $(\mathrm{P}<0,05)$ em relação ao intermitente e luz natural e nestes últimos não ocorreu diferença $(\mathrm{P}>0,05)$.

\section{Discussão}

Observa-se na produção de ovos que as aves submetidas aos programas intermitente e luz natural decrescente não conseguiram manter o mesmo índice de produtividade que o contínuo de $16 \mathrm{~h}$. À medida que foi encurtando o tempo de luminosidade natural (quarto e quinto períodos), as aves tiveram redução da produção de ovos. Isto é um indicativo que as poedeiras modernas ainda reagem a estimulação quando submetidas a fotoperíodos longos. Entretanto, o percentual de redução da postura não é de 20 a $40 \%$ como escrito por Cotta (2002), pois no quinto período, onde o fotoperíodo natural foi $10: 07 \mathrm{~h}$, a diferença percentual observada foi $8,6 \%$ entre o programa contínuo e intermitente e 7,6\% entre o contínuo e natural. Ressalta-se que o menor tempo de fotoperíodo natural no ano indicado para a Região Sul do País é 10:06h (COTTA, 2002).

TABELA 2: Massa (g), peso $(\mathrm{g})$ e peso específico $\left(\mathrm{g} / \mathrm{cm}^{3}\right)$ de ovos de poedeiras semipesadas modernas submetidas durante 5 períodos de 28 dias a programas de iluminação contínuo (CON), intermitente (INT) e luz natural decrescente $(\mathrm{LND})^{*}$.

\begin{tabular}{cccc|ccc|ccc}
\hline \multirow{2}{*}{ Período } & \multicolumn{3}{c}{ Massa de ovos } & \multicolumn{3}{c|}{ Peso de ovos } & \multicolumn{3}{c}{ Peso específico } \\
\cline { 2 - 10 } & CON & INT & LND & CON & INT & LND & CON & INT & LND \\
\hline 1 & 30,1 & 27,1 & 27,4 & $58,8^{\mathrm{a}}$ & $57,3^{\mathrm{b}}$ & $56,4^{\mathrm{b}}$ & 1093 & 1094 & 1094 \\
2 & $59,4^{\mathrm{a}}$ & $54,4^{\mathrm{b}}$ & $56,5^{\mathrm{ab}}$ & $62,8^{\mathrm{a}}$ & $59,9^{\mathrm{b}}$ & $60,9^{\mathrm{b}}$ & $1101^{\mathrm{a}}$ & $1091^{\mathrm{b}}$ & $1092^{\mathrm{b}}$ \\
3 & $61,6^{\mathrm{a}}$ & $58,1^{\mathrm{b}}$ & $56,7^{\mathrm{b}}$ & $65,0^{\mathrm{a}}$ & $64,0^{\mathrm{a}}$ & $61,8^{\mathrm{b}}$ & 1090 & 1090 & 1090 \\
4 & $63,2^{\mathrm{a}}$ & $58,3^{\mathrm{b}}$ & $57,5^{\mathrm{b}}$ & $65,9^{\mathrm{a}}$ & $64,8^{\mathrm{b}}$ & $63,2^{\mathrm{b}}$ & 1090 & 1090 & 1090 \\
5 & $64,8^{\mathrm{a}}$ & $58,6^{\mathrm{b}}$ & $57,2^{\mathrm{b}}$ & $68,0^{\mathrm{a}}$ & $66,5^{\mathrm{b}}$ & $65,7^{\mathrm{b}}$ & 1090 & 1089 & 1089 \\
\hline $\mathrm{CV} \%$ & & 7,00 & & & 2,72 & & & 0,68 & \\
\hline
\end{tabular}

*Letras diferentes entre as variáveis nas linhas diferem significativamente pelo Teste Tukey $(\mathrm{P}<0,05)$. 
Esta redução na diferença entre um programa contínuo e a luz natural acorda com Charles e Tucker (1993) e Sauveur (1996) que citam que as aves vêm perdendo progressivamente a sensibilidade à luz devido à pressão de seleção exercida pelas empresas de melhoramento genético que disponibilizam linhagens modernas aos produtores.

O tempo de $2 \mathrm{~min}$ das fotofases do programa intermitente não foi suficiente para estimular a produção de ovos. Este resultado discorda do encontrado por Melo et al. (2006) testando programa intermitente em codornas que indicaram a viabilidade do uso deste programa já no início do período de postura. No entanto, é de se ressaltar que o tempo das fotofases neste ensaio (inicial e final) foi de $30 \mathrm{~min}$ entre a luz natural e em $17 \mathrm{~h}$ para codornas.

O consumo de ração, nos diferentes tratamentos, foi o esperado, que é o aumento entre os períodos devido à idade. Entretanto, ocorreu uma leve redução no terceiro período.

Observa-se que o consumo de ração nos tratamentos é superior ao indicado ao manual da linhagem que é de $115 \mathrm{~g} /$ dia. De fato, o maior tempo de exposição das aves à luz predispõe a um aumento do consumo de ração. Já no terceiro período observou-se diferença entre os programas. Já a diferença observada entre o programa intermitente e luz natural é um indicativo que as fotofases podem interferir no consumo.

No quinto período, a diferença percentual no consumo de ração entre o programa contínuo e o intermitente foi de $8,4 \%$ e, entre o contínuo e o luz natural foi de 11,4\%. Alguns autores (FREITAS, 2003; GEWEHR, 2003) já haviam indicado que programas intermitentes e luz natural em galpões abertos reduzem consumo, entretanto estes programas não causavam redução da produção de ovos. Contudo, estes trabalhos haviam sido conduzidos com aves já treinadas, a partir de 36 semanas de idade.

A conversão alimentar teve um resultado considerado interessante, onde no quarto e quinto períodos, quando os tempos de exposição das aves foram menores, ocorreu redução da conversão, ou seja, um menor tempo de exposição a luz melhora a conversão alimentar.
Por este resultado observado na conversão alimentar não se pode destacar a eficiência dos programas alternativos (intermitente e natural). Isto porque, trata-se de um resultado derivado da relação entre o consumo de ração e peso de ovos, e ao se observar o resultado destes dois quesitos não se observa a diferença estatística.

A massa de ovos tem sido usada para avaliar o desempenho de um lote de poedeiras. Assim, o programa contínuo propicia uma melhor massa de ovos em relação ao programa intermitente e luz natural. Esta melhora já foi percebida a partir do segundo período de avaliação.

O peso de ovos foi maior no programa contínuo em relação aos demais programas. Esta diferença foi observada em todos os períodos e pode ser atribuída ao menor consumo de ração. Sobre esta situação, ressaltase que o peso dos ovos sofre influencia do tempo que as galinhas ficam expostas à luz, e este maior tempo de luz conduz a um maior ao consumo de ração. Gewehr et al. (2005) haviam observado a relação de um menor consumo de ração e menor peso de ovos em codornas em um tipo de programa intermitente quando comparado a um contínuo de 17:30h.

O peso específico também tem sido utilizado como prática rotineira em granjas para verificar a qualidade da casca de ovos. Este procedimento é assegurado porque a densidade da casca de ovos é duas vezes maior que a densidade da gema e do albúmen. Neste contexto, observou-se diferença apenas no segundo período, sendo maior no contínuo em relação aos demais programas. Esta diferença pode ser atribuída à alta temperatura ambiental verificada nos dias que se realizou a coleta dos ovos para análise, onde uma ave com maior tempo de exposição à luz, tem as horas mais frescas do dia (madrugada e noite) para consumir ração, o que de certa forma é um método de estimular consumo de ração que tem relação direta com a qualidade da casca. Excetuando-se este segundo período, observa-se que os programas de iluminação não têm interferência sobre a qualidade da casca de ovo.

A partir dos resultados obtidos, conclui-se que poedeiras semipesadas modernas ainda têm a produção de ovos estimulada quando submetidas a programa de iluminação contínuo de 16h. Programa intermitente com 
fotofases de $2 \mathrm{~min}$ e programa de luz natural decrescente não são eficientes para serem fornecidos às poedeiras semipesadas no início do período de postura.

\section{Referências}

CAMPOS, E. J. Avicultura: Razões, fatos e divergências. Belo Horizonte: FEPE-MVZ, 2000. 311 p.

CHARLES, D. R.; TUCKER, S. A. Response of modern hybrid laying strocks to change in photoperiod. British Poultry Science, London, v. 34, p. 241-254, 1993.

COTTA, J. T. de B. Galinha: produção de ovos. Viçosa: Aprenda Fácil, 2002. 191 p.

ERNST, R. A.; MIILLAM, J. R.; MATTHER, F. B. Review of lifehistory lighting programs for commercial laying fowls. World's Poultry Science Journal, Cambridge. v. 43, p. 44-55, 1987.

ETCHES, R. J. Reproducción aviar. Zaragoza: Acribia, 1996. $339 \mathrm{p}$.

FREITAS, H. J. Avaliação de programas de iluminação para poedeiras leves e semi-pesadas. $2003.99 \mathrm{f}$. Tese (Doutorado em Zootecnia) - Universidade Federal de Lavras, Lavras. 2003.

FREITAS, H. J. DE; COTTA, J. T. de B.; OLIVEIRA, A. I. de; GEWEHR, C. E. Avaliação de programas de iluminação sobre o desempenho zootécnico de poedeiras leves. Ciência e Agrotecnologia, Lavras, v. 29, n. 2, p. 424-428, 2005.

GEWEHR, C. E. Avaliação de programas de iluminação em codornas (Coturnix coturnix). 2003. 81 f. Tese (Doutorado em Zootecnia) - Universidade Federal de Lavras, Lavras. 2003.
GEWEHR, C. E.; COTTA, J. T. de B.; OLIVEIRA, A. I. de; FREITAS, H. J. de. Efeitos de programas de iluminação na produção de ovos de codornas (Coturnix coturnix). Ciência e Agrotecnologia, Lavras, v. 29, n. 4, p. 857-865, 2005.

GEWEHR, C. E.; FREITAS, H. J. de. Iluminação intermitente para poedeiras criadas em galpões abertos. Revista de Ciências Agroveterinárias, Lages, v. 6, n. 1, p. 54-62, 2007.

LITTEL, R. C.; MILLIKEN, G. A.; STROUP, W. W.; WOLFINGER, R. D.; SCHABENBERGER, O. SAS ${ }^{\circledR}$ for mixed models. 2. ed. Cary: SAS Institute Inc., 2006. 834 p.

MELO, L. M.; MURGAS, L. D. S.; OLIVEIRA, B. L.; ZANGERÔNIMO, M. G. Utilização de programas de iluminação contínuo e intermitente em codornas (Coturnix coturnix). In: REUNIÃO ANUAL DA SOCIEDADE BRASILEIRA DE ZOOTECNIA, 43, 2006, João Pessoa. Anais... João Pessoa: SBZ, 2006.

ROSTAGNO, H. S.; ALBINO, L. F. T.; DONZELE, J.; GOMES, P. C.; OLIVEIRA, R. F.; LOPES, D. C.; FERREIRA, A. S.; BARRETO, S. L. de T. Tabelas brasileiras para aves e suínos: Composição de alimentos e exigências nutricionais. Viçosa: UFV, 2005. 186 p.

ROWLAND, K. W. Intermittent lighting for laying fowls: A review. World's Poultry Science Journal, Cambridge, v. 41, p. 5-20, 1985. SAS - Institute Inc ${ }^{\circledR}$. SAS Version 9.1.3. Cary: SAS Institute Inc., 2003. Versão eletrônica.

SAUVEUR, B. Photopériodisme et reproduction des oiseaux domestiques femelles. INRA Productions Animales, Paris, v. 9, p. 25-34, 1996

STEEL, R. G. D.; TORRIE, J. H.; DICKEY, D. A. Principles and procedures of statistics - A biomerical approach. 3. ed. New York: McGraw-Hill, 1997. 666 p. 